\title{
The Role Of Project Success In The Relationship Between Accountability And IS Process Documentation
}

Chih-Chen Lee, (E-mail: cclee@niu.edu), Northern Illinois University

Krishnamurthy Surysekar, (E-mail: suryseka@fiu.edu), Florida International University

Te-Wei Wang, (E-mail: Twang22@uis.edu), University of Illinois at Springfield

\begin{abstract}
We report on an experimental study of the impact of outcome bias and accountability on documentation decisions. The subjects, working on an information system development project, decided on how much of the process details (both good and bad) known only to the project team, would be made part of an intra-organizational knowledge database. We find that outcome bias has a significant influence on decisions. Managers of "failure" projects were more inclined to report more of the bad process details than managers of "successful" projects, consistent with attribution theory.
\end{abstract}

\section{INTRODUCTION}

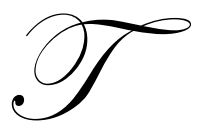

his study is to examine organizational policies that have the potential to improve the completeness of process documentation. Process documentation is an essential topic in system development methodology studies. Regardless of the project management process, most IS methodologies rely on process documentation, in either digital or paper forms, to control and to improve their processes. As CMMI (Capability Maturity Model Integration) specialists, Margaret Kulpa and Kent Johnson, described, clear and detailed process documentation is not "for show." "It is necessary documentation (Kulpa \& Johnson, 2003, p. 173)." We also consider that a successful documentation practice is important to the long term success for project-oriented organizations, such as firms that develop and implement information systems. For instance, Markus (2001) documents efforts made in technology consulting firms like Booz Allen Hamilton to encourage employees to actively create and share experiences that they learned from past projects. In organizations like Booz Allen Hamilton, the processes of knowledge creation and sharing depend heavily on project documentation, especially those documenting project processes (Schindler \& Eppler, 2003).

The study of process documentation also links to knowledge management research. In their comprehensive review of knowledge management (KM) and knowledge management systems (KMS), Alavi and Leidner (2001, p. 107) note that "the objective of KMS is to support creation, transfer and application of knowledge in organizations." They further note (p. 129) that "research that focuses on social, cultural, and technical attributes of organizational settings that encourage and facilitate knowledge flows.....is important.” If knowledge sharing is indeed important, then the question is what determines the extent of knowledge sharing. In the context of IS development, models and documentation are the main tools for preserving, sharing and transferring knowledge.

In this paper, we report on the results of our experimental study. In the context of IS development projects, we draw from research in individual and social psychology to explore the effect of two factors - accountability and perceived project outcome, on the completeness of project documentation. We looked at the decision of the subjects to disclose privately held, project-specific information to the organizational database. We considered the influence of accountability (need to justify their decisions to a reviewer) and outcome bias (whether the project was deemed a success or a failure) on this decision. 
Our main results are as follows. Consistent with attribution theory, we find that subjects who managed a failure project significantly disclosed more of the bad process details in their documentation than subjects who managed a successful project. Further, consistent with some prior experimental work, we did not find a significant influence of accountability on the disclosure decisions made by the subjects.

Since our results support the notion that a perception of success or failure of the project significantly affects the completeness of process documentation about the project, they provide a way for firms to "manage" the perception of "success" or "failure" to induce a more useful contribution to internal knowledge databases. Such is already being practiced via iterative processes that are a feature of modern IS methodologies. In these iterative methodologies, project deadline, project scope, and project outcomes (as defined in the present paper) are all made ambiguous. Our study points to a possible unanticipated benefit of "under-defined" project outcomes, i.e., a reduced need for employees to bias the documentation

Our paper is organized as follows. In Section 2, we discuss the importance of and prior research into process documentation and its determinants. In Section 3, we discuss the design our experimental study. We provide the results in Section 4. Section 5 has the discussions and conclusions. We discuss the limitations of our study and suggest avenues for future work in Section 6.

\section{THE IMPORTANCE OF PROCESS DOCUMENTATION}

Documentation is required in most modern IS development methodology. Process documentation, relating to process improvement, technical know-how and project experience, are especially important. To learn from project experiences, many organizations have adopted certain project documentation policies. For instance, IBM Consulting Group uses a project document called End of Engagement Summary as an official step to close consulting projects (Schindler \& Eppler, 2003). Nonetheless, most project documents focus on explicit knowledge that is relatively easy to document. Project experiences such as those leading to problem-solving mechanisms, are usually known only to the people who are personally involved in the projects. Extracting these experiences from these individuals and making them available to the rest of the organization helps the firm to leverage on this knowledge base in the future. Schindler and Eppler (2003, p. 227) note that "one has to view the project's outcome not only in terms of its physical or tangible results, but also as a contribution to the company's knowledge base."

Managing project experiences is part of tacit knowledge management. In the last decade, a prominent conceptual framework for the study of organizational knowledge management process is provided in Nonaka (1994) and Nonaka et al (2000). Nonaka (1994) posits that both individual efforts as well as organizational factors play a role in the creation of knowledge in organizations. Nonaka identifies four processes of knowledge conversion in organizations involving the interactions of tacit and explicit knowledge - socialization, externalization, internalization and combination. This conceptual framework is also known as the SECI model (Nonaka \& Konno, 1998). Socialization converts tacit knowledge in individuals to organization-wide tacit knowledge through interactions. Externalization involves the conversion of tacit knowledge to explicit knowledge. Internalization converts explicit knowledge to tacit knowledge. Finally, combination converts explicit knowledge to different forms of explicit knowledge and supports future knowledge creation processes. In addition, Nonaka et al (1998; 2000) stress the importance of management of knowledge assets in the creation of knowledge in organizations. As they point out (2000, p. 22), management of the knowledge creating process should recognize that "...new knowledge assets can be created from existing knowledge assets." In the present paper we are interested in a particular form of knowledge asset - process documentation.

We define 'process documentation' as it is generally understood in the project management literature. It is "documentation of information about how a project team made decisions at different stages of the project, the pitfalls and bumps along the road and how they were resolved" (Schindler \& Eppler, 2003). Formal process documentation is an important means of knowledge transfer in organizations. Indeed, proper documentation can lead to the identification of "best practices" for development methodologies. The popular Unified Rational Process, for instance, includes a post-implementation review document as a major requirement during the "transition" stage (Kruchten, 
2003, p. 64). The main idea of such a document is that documented success can be repeated and failure can be avoided (Stumpf \& Teague, 2004, p. 45).

In the project management literature, researchers have called for the process document to capture tacit project knowledge (e.q., Kerth, 2000; Liu, Dooley, \& Anderson, 1995; Schindler \& Eppler, 2003). Further, as pointed out in Ramesh and Surysekar (2003), firms that develop information products appreciate a critical need for capturing the rationale behind decisions made in a project, so that teams that work on subsequent projects can learn from this process documentation. Unfortunately, knowledge and experiences gained in different projects are not usually captured in the organizational knowledge base (Ramesh, 2002; Schindler \& Eppler, 2003). Details, especially those related to mishaps, mistakes and potential pitfalls are not provided in the process documentation of many knowledge organizations (Collier, DeMarco, \& Fearey, 1996; Ramesh \& Surysekar, 2003).

The question of how much efforts and what contents should a corporation knowledge base include still remains to be determined (Alavi \& Leidner, 2001). Whether or not organizations should allocate more resources to process documentation is a debatable question. However, we do know from the previously cited literature that process documentation does serve an organization beyond its role as part of the organization's knowledge base. It can be a vital instrument in facilitating the SECI process. First, process-based learning alleviates deficiencies with other forms of learning like debriefing workshops that are moderated by project managers, and formal documents prepared for the client (Schindler \& Eppler, 2003). It contains multiple forms of explicit knowledge. Documents about successful project process can capture procedural (know how) knowledge (Alavi \& Leidner, 2001) while decisions made in failure projects can generate causal (know why), conditional (know when), and relational (know with) knowledge (Alavi \& Leidner, 2001; Schindler \& Eppler, 2003). Second, process documentation contains abundant information for people in organization to discuss, comment on, or criticize. Thus, it can serve as a useful resource for the socialization process (Nonaka \& Konno, 1998). Third, individuals can actually learn through the process of creating process documentation (Karina, 1998). For instance, in Bernhardt and McCulley's study (2000) on pharmaceutical development teams, they found that documenting the process can help a person to organize his/her idea better, clarify ambiguities faster, and thus shorten the time it takes for new product development. They also found that detailed process documentation and the process of creating that documentation could encourage team members to actively seek evidences, to socialize with other team members, and to follow both organizational and governmental regulations (Bernhardt \& McMulley, 2000). We believe that such documents have similar effects on IS development teams. In summary, a good process documentation practice is a positive force in promoting the SECI process. A 'knowledgeconscious' organization should devote efforts whenever possible to create and to maintain comprehensive process documentation.

\section{Factors That Affect Process Documentation}

Recognizing the importance of comprehensive process documentation, organizations may create monetary and/or other incentives for employees to provide comprehensive process documentation in order to make it available for other employees in the organization. However the comprehensiveness and the reliability of such documentation may depend on a number of factors. These factors may include the following (Schindler \& Eppler, 2003): time pressure, individual's willingness, miscommunication, lack of knowledge, etc. Based on these factors, many mechanisms can be developed to promote process documentation ${ }^{1}$

In this paper, we examine two factors: an organizational factor (accountability), and a situational factor (perceived project outcome). We examine how accountability and perceived project outcome affect the decision of the employee to generate comprehensive documentation of the project. ${ }^{2}$

\footnotetext{
${ }^{1}$ (see Alavi \& Leidner, 2001 for detail discussion).

${ }^{2}$ We do not examine the effect of monetary incentives in this paper. The reason is that the "comprehensiveness" of documentation cannot be perfectly verified for organizations to create explicit monetary incentives for them. Further, Gibbons (1998) has noted serious limitations of monetary incentives in many organizational contexts.
} 


\section{Accountability And Process Documentation}

There is a significant body of literature on the effect of accountability on decisions. Accountability is one of the mechanisms observed in many organizations (Lerner \& Tetlock, 1999). In general, accountability has been defined as "the requirement to justify one's judgment to others" (Kennedy, 1993, p. 231). It is the "implicit or explicit expectation that one may be called on to justify one's beliefs, feelings and actions to others”(Lerner \& Tetlock, 1999). Gibbins and Emby (1985) note that the ability to justify decisions is equivalent to greater documentation efforts.

Accountability has been shown to affect people's decision-making process. Tetlock (1983) suggests that when people are held accountable for their decisions, these decisions tended to follow the "anticipatory opinion" of the evaluators. For example, Turner (2001), using an experimental study, reports that auditors' search strategies were consistent with the expressed concerns of their reviewers. Auditors who faced reviewers concerned about too much time being spent on items that were inconsistent with the client's explanations tended to follow a search that was prompted by the client. Hoffman and Patton (1997) and Peecher (1996) showed similar results in different task settings. Johnson and Kaplan (1991) show that auditors who were told that their decisions would be subject to review and required justification led to greater consensus in the decisions, and showed greater evidence of self-monitoring.

For process documentation, in general, we argue that employees' decisions on preparing comprehensive documents depend on their perceptions of the organization's expectation. We expect that if an organization expects their members to create comprehensive documents, the employees would document accordingly. However, organizations usually have multiple expectations toward their members. Therefore, the members would tend to prioritize these expectations before making any decisions on what should be included in a process document. For instance, Fox and Staw (1979) conducted an experiment to test how employees make their decisions when under the pressure of job insecurity and accountability to create accurate accounting documents. They found that people have hard time writing off "sunk costs" and admitting mistakes that led to these "sunk costs". In the experiment, subjects were trying to balance the two expectations, manage cost well and generate a correct report, before making decisions. The theoretical question now is 'how do people, especially IS developers, cope with accountability under different social expectations?'

To explain how people make decisions under accountability and multiple sources of social expectation, Tetlock (1985) proposed and tested experimentally (Tetlock, Skitka, \& Boettger, 1989) a contingency theory called social contingency model (SCM). The SCM assumes that "people rely on simple, low-effort heuristics that allow them to make up their minds quickly, easily, and with confidence in their judgments”(Tetlock et al., 1989, p. 633). In their own words, people performing decision making are "cognitive misers"(Tetlock, 1985; Tetlock et al., 1989). Three possible responses might come from a cognitive miser: acceptability heuristic, preemptive self-criticism, and retrospective rationality. When no accountability is present, a cognitive miser can be expected to take the most salient, simple, and socially acceptable position (acceptability heuristic) in making decisions. They would probably follow what other people do in the decision-making process. When the decision-making mechanism is not well known to others and the subject is under ambiguous accountability pressure, cognitive misers will engage in preemptive selfcriticism, a process of anticipating the objections of potential critics, before making their decision. Finally, when people feel clear accountability for their decision and the decision mechanism is publicly known, the majority of the mental effort goes into generating thoughts that justify their original commitments (retrospective rationality).

Applying the SCM in the context of generating comprehensive process documentation from an IS project, one can expect that people have the tendency to be conservative in reporting process details. When there is no accountability pressure, project members may report the minimal information required by the organizations because it is the most convenient and politically correct way of doing things. If accountability pressure is present, project members may take one of two courses of actions. The first possibility is conducting serious consideration before including detailed process descriptions. They will do so due to the uncertainty of consequences. In such conditions, sensitive material may be excluded from their documents to avoid possible criticism (from both within and outside the project team). Second, when process details have already been exposed through other mechanisms in the organization, such as gossips, project members might choose to include certain details and try to justify their decisions made in the 
project. Between these two possible responses, the former is much more likely since most accountability pressure is ambiguous in enforcing process documentation.

\section{Outcome Accountability Versus Process Accountability}

From the above discussion on SCM, it appears that accountability may not guarantee process documentation efforts. Should organizations continue to use accountability as part of their project management policy? Answers to this question are not definite. Recent accountability studies that differentiate different types of accountability may shed some light on this issue.

Simonson and Staw (1992) proposed different types of accountability: outcome accountability and process accountability. Outcome accountability refers to the expectation of justification on a subject's decision outcome (Lerner \& Tetlock, 1999). On the other hand, process accountability held subjects accountable for the quality of decision-making process (Lerner \& Tetlock, 1999). At least two empirical studies confirm that process accountability can better reduce decision bias compared to outcome accountability (Siegel-Jacobs \& Yates, 1996; Simonson \& Staw, 1992). Nonetheless, the two studies are based on the assumption that a clear identifiable decision process is present. This is not the case in most iterative IS methodologies. In the case of process documentation, people are held accountable for the final documents (outcome accountability) instead of the process of making documents (processs accountability).

Thus, our study is exploratory in nature. The literature is not clear on how to hold IS developers accountable for the process of making the documents, and also if the outcome accountability will improve the comprehensiveness of process documentation. Therefore, our first hypothesis is stated in the null form:

H1: The presence of accountability will not affect the comprehensiveness of process documentation.

\section{Project Outcome And Process Documentation}

Both Fox and Staw's studies and Tetlock's theory discussed earlier indicate that, under accountability pressure, people tend to minimize detrimental effects that could happen to them. It is very likely that people choose to report good decisions rather than bad ones (Lipshitz \& Barak, 1995; Tetlock et al., 1989). Nonetheless, organizations should encourage (if possible) its members to report mistakes made in the past since bad decisions and decisions leading to unfavorable outcomes may contribute more to an organization in the knowledge creating process (Alavi \& Leidner, 2001; Ramaprasad \& Rai, 1996; Schindler \& Eppler, 2003; Stumpf \& Teague, 2004).

People's willingness to report mistakes may be further complicated by situational factors such as project outcomes (Lipshitz \& Barak, 1995).The role of project outcome in decisions has been experimentally investigated in Church et al (1999). They conducted an experimental study involving the tendency of managers to continue to invest in poorly performing capital projects. In this multi-period study, one group of participants were told that their organization would support their decision to withdraw from a poorly performing capital project and another group was informed that there would be severe performance consequences to withdrawing from a project, which would be taken as implicitly admitting the mistake of investing in the project in the first place. One interesting finding of this study was that both groups of participants continued to invest in a poorly performing project. Church et al's (1999) study implies that people tend not to admit their own mistakes even when available outcome information and a supportive organizational culture would suggest they do otherwise.

There is a competing argument regarding to the effect of project outcome on the comprehensiveness of process documentation. According to attribution theory (Kelley, 1967; Lerner \& Tetlock, 1999), project members would find reasons to explain the outcome of their decision. When the project is a success, they would tend to not disclose bad decisions in their process documentation and only include the good decisions they made in the process of completing the successful project. However, when the project is a failure, team members might perceive a need to include the bad decisions in their documentation to explain the unfavorable outcome. Due to the competing arguments, we state our second hypothesis in the null form: 
H2: Process outcome does not have an effect on the comprehensiveness of process documentation.

\section{RESEARCH DESIGN}

We conducted a laboratory experiment to test the above two hypotheses. Subjects role-played project team members and were provided with the experimental scenario. Subjects made decisions as to how comprehensive their process documentation would be. The experimental scenario dealt with process documentation in a software development project.

\section{Subjects}

Our sample consisted of 174 undergraduate students majoring in accounting and MIS at a state university. They had an average age of 25 (range from 19 to 45). Males constituted 57 percent of the sample. The students were offered extra course credit for their voluntary participation in this experimental study. We also measure subjects' attitude toward comprehensive process documentation (Honesty) by asking the following four questions:

- $\quad$ In project documentation it is ok to withhold information that is not publicly known.

- $\quad$ A document is comprehensive even though it may leave out details that could embarrass the project team.

- $\quad$ It is ok to withhold information in the project documentation if the whole team feels that way.

- Information may be private to the project team now but it has a way of becoming public knowledge in the future.

The mean response was 2.8 on a 5-point ( $1=$ disagree completely) Likert scale, indicating that subjects were somewhat favorably disposed to preparing comprehensive process documentation. It is possible that the subjects' attitude toward honest reporting would affect their decision to prepare comprehensive process documentation. Therefore, the honesty score is included as a covariate for the analysis of variance.

\section{The Experimental Project}

The software development project was to modify a sales transaction application. Our assumption about each software project is similar to the concept of "iteration" in most modern methodology. It had four generic stages:

$$
\begin{array}{ll}
- & \text { requirement gathering } \\
\text { - } & \text { analysis and design } \\
\text { - } & \text { building a prototype } \\
& \text { modification and implementation }
\end{array}
$$

In each stage, all the subjects were given details on how that stage was completed, including some mistakes that were made. We refer to these details as "process details". For instance, in the requirement gathering stage, all the participants were told that some essential information that should have been gathered the first time around was not, and a second round of interviews with the clients became necessary. Due to this, some time was lost and an experienced system designer worked overtime to make up the lost time. All participants were told that only the team members know these process details.

The core details above were given to all participants. Then the participants were randomly assigned to groups that differed in perceived project outcome (success versus failure) and accountability (yes versus no), as provided in Exhibit 1 below. 
Exhibit 1

Experimental Design

\begin{tabular}{|l|c|c|}
\hline & \multicolumn{2}{|c|}{ Perceived Project Outcome } \\
\hline Accountability & "Success” & "Failure” \\
\hline “Accountable” & Group I & Group II \\
\hline “Non-accountable” & Group III & Group IV \\
\hline
\end{tabular}

The project outcome was deemed a success if the client is satisfied and the project completed on time. Project outcome was deemed a failure if the client is dissatisfied and the project not completed on time. Consistent with Kennedy (1993) accountability is defined as the need to (in the minds of the subjects) justify the decisions made to a superior. The "accountable" group was informed that a senior systems analyst would review their process documentation, and that they would need to justify their documentation to this individual. This information was not given to the non-accountable group. However, all the groups were clearly informed that only their group knew the "process details".

Since the process details are the same for all participants, they were given a list of these details (both the "good" and the "bad"). The decision they had to make was whether or not they would disclose each of these items in their process documentation. ${ }^{3}$

\section{Dependent Variables}

We tallied the good items and the bad items each subject decided to include in the process documentation, resulting in the total good item score (hereafter: GTotal; min 4, max 16), and the total bad item score (hereafter: BTotal, min, 4; max, 16). We also calculated the excess of (Diff) the number of bad items over the number of good items subjects decided to include in the process documentation. Thus, a negative value for Diff indicates that the subjects reported less bad items than the good items.

\section{RESULTS}

We ran the manipulation check for accountability and perceived project outcome and they were manipulated successfully. Descriptive statistics (mean and standard deviation) of the dependant variables are reported in Table 1 below.

Table 1: Descriptive Statistics (Mean (Standard Deviation) Of Dependent Variables

\begin{tabular}{|c|c|c|c|c|}
\hline & \multicolumn{2}{|c|}{ Accountable } & \multicolumn{2}{|c|}{ Non-Accountable } \\
\hline & Success & Failure & Success & Failure \\
\hline GTotal & $\begin{array}{c}3.45 \\
(0.92)\end{array}$ & $\begin{array}{c}3.14 \\
(1.03)\end{array}$ & $\begin{array}{c}3.14 \\
(1.09)\end{array}$ & $\begin{array}{c}3.33 \\
(0.95)\end{array}$ \\
\hline BTotal & $\begin{array}{c}2.40 \\
(1.40)\end{array}$ & $\begin{array}{c}2.67 \\
(1.18)\end{array}$ & $\begin{array}{c}2.00 \\
(1.40)\end{array}$ & $\begin{array}{c}2.50 \\
(1.44)\end{array}$ \\
\hline Diff & $\begin{array}{l}-1.05 \\
(1.46) \\
\end{array}$ & $\begin{array}{c}0.48 \\
(1.57) \\
\end{array}$ & $\begin{array}{l}-1.14 \\
(1.47) \\
\end{array}$ & $\begin{array}{l}-0.83 \\
(1.68) \\
\end{array}$ \\
\hline
\end{tabular}

GTotal: Number of good items included in documentation BTotal: Number of bad items included in documentation Diff: BTotal-GTotal

From Table 1, it is evident that subjects with "Failure" projects reported, on average, more bad items (BTotal) than the subjects in "Success" projects. This is true for both the Accountable (2.67 vs. 2.4) and the NonAccountable (2.5 vs. 2.0) groups. Furthermore, subjects in the "Accountable” group report more bad items than

\footnotetext{
${ }^{3}$ The complete project scenario provided to each of the four groups is available from the corresponding author upon request.
} 
subjects in the "Non-accountable" group. This is true for both "Success" projects (2.4 vs. 2.0) and the "Failure" projects (2.67 vs. 2.5).

Considering both good items (GTotal) and bad items (BTotal), Table 1 also shows that the variable "Diff", which is the excess of BTotal over GTotal, exhibits the same pattern as the variable "BTotal" discussed in the previous paragraph.

To test our hypotheses, we perform the 2 (accountability: yes vs. no) X 2 (project outcome: success vs. failure) analysis of co-variance (ANCOVA) with the Btotal, Gtotal, and Diff as dependent variables and Honesty as the covariate. Table 2 reports the ANCOVA results with the dependent variable as the Btotal. The overall model is significant $(\mathrm{F}=8.74, \mathrm{p}<.0001)$.

Table 2: Analysis Of Covariance With Dependent Variable As Btotal

\begin{tabular}{lcccc}
\hline Source of Variation & SS & df & F-Ratio & p-value \\
\hline Accountability (Acc) & 3.20 & 1 & 2.05 & .1541 \\
Project outcome & 8.07 & 1 & 5.18 & .0243 \\
Acc Project outcome & 1.18 & 1 & .76 & .3855 \\
Honesty & 42.07 & 1 & 29.97 & $<.0001$ \\
\hline
\end{tabular}

The ANCOVA results show that project outcome is significant $(F=5.18, p=.0243)$. Subjects who perceived the project to be a failure tend to include more bad items in the process documentation than the subjects who perceive the project to be a success (The means were 2.585 and 2.000 respectively, with a t statistic of 1.82 and a p-statistic of 0.07). Accountability and the interaction between accountability and project outcome are not significant.

Table 3 reports the ANCOVA results with the dependent variable as the Diff. The overall model is significant at $0.01(\mathrm{~F}=4.02, \mathrm{p}=.004)$. Again, the only variable that is significant is project outcome.

Table 3: Analysis Of Covariance With Dependent Variable As Diff

\begin{tabular}{lcccc}
\hline Source of Variation & SS & df & F-Ratio & p-value \\
\hline Accountability (Acc) & 1.54 & 1 & 0.69 & .4081 \\
Project outcome & 11.06 & 1 & 4.94 & .0277 \\
Acc•Project outcome & 0.48 & 1 & .22 & .6425 \\
Honesty@ & 22.86 & 1 & 10.21 & 0.0017 \\
\hline
\end{tabular}

Honesty@ score was highly correlated with the sex of the subjects.

It is clear that Hypothesis 2 is supported. Project outcome is significant from Tables 2 and 3. We also ran ANCOVA with GTtotal as the dependant variable. The results were not significant. This is consistent with our results in Tables 2 and 3. The subjects' decision on the "good" items to report was unaffected by either perceived project outcome or accountability. This result is also similar to the observed result in Church et al (1999), where subjects persisted with poorly performing projects irrespective of whether the organization was supportive or nonsupportive of withdrawing from such projects.

Finally, we found that the term "Diff" is more for failure projects than for success projects $(\mathrm{t}=1.85$ and $\mathrm{p}=0.07$ ). Noting that "Diff" is the excess of bad items reported over the good items reported, this shows that failure project teams showed a higher inclination to report more bad items than good items, as compared to teams working on successful projects. This provides support to attribution theory. 


\section{DISCUSSION AND CONCLUSIONS}

We set out to experimentally study the determinants of comprehensive process documentation in systems development projects. Specifically, we considered the impact of perceived outcome bias and accountability. Perceived project outcome has emerged as a significant determinant of comprehensive process documentation. This result is consistent with the idea that people tend to "justify" themselves in the documentation process. However, we did not find significant support for the impact of accountability on comprehensive process documentation. This could be a result of the participants in our experiment not seeing accountability as "enforceable." We defined accountability for process documentation as a review of the document by a senior systems analyst and possible questioning of the project team by this individual on its contents. However, the items the team could have disclosed were private information to the team. It is possible that the participants believed that these could never be unearthed by the reviewer.

Our results have some implications for firms looking to enhance the quality of their system documentation. Since perceived outcome success has an effect on the comprehensiveness of process documentation, it provides an opening for companies to manipulate the perception of "success" to extract better process documentation. In Balakrishnan et al (2004), it is shown that companies could use performance evaluation systems to motivate employees to provide long-term efforts for the company, knowing that they could be fired before such efforts could bear fruit.

The findings from our study provide some support to the practice of iterative development. Modern IS methodologies, in general, promote an iterative process. These processes de-emphasize the importance of a clear project boundary. Project deadlines, project scope, and project outcomes (as defined in the present paper) are all made ambiguous in iterative development. Our study finds an unanticipated benefit of "under-defined" project outcomes, i.e., a reduced need for employees to bias the documentation.

Lengthy documentation, are frequently discouraged in modern systems methodologies. However, this does not mean that documentation is not important. In fact, documentation should be "agile" as well (Larman, 2004, p. 326). Agile documentation encourages only "necessary" documents and pair (two-person) "documentation teams" (Larman, 2004, p. 327). This "pair" documentation practice separates the documentation responsibility from the overall project responsibility. Also, to make the process agile, external audit is discouraged. This recommendation is consistent with our results. The accountability policy, using an external auditor to review documentation quality, may be counter-productive. It might be better to make documentation a team approach. It might also be advantageous to stress the knowledge sharing benefit over the formal requirement aspect of process documentation. Both of the above suggestions would imply that project team members' intrinsic motivations are more important than accountability to ensure the completeness of process documentation.

The overall conclusion that could be drawn is that project outcome appears to be a more important influence on this particular (IS project) documentation decision than accountability. This has interesting implications for organizations working to create a credible intra-organizational knowledge database. Clearly, consistent with attribution theory, participants were more inclined to reveal private information that is likely to show them in poor light, when the outcome has already shown them in poor light. On the other hand, absent any possible ex-post verification of process details, accountability cannot go far in providing completely credible process documentation.

\section{LIMITATIONS AND POSSIBLE EXTENSIONS}

This was an exploratory study, given the mixed nature of prior theoretical guidance on the question we studied. One limitation of our study was not considering the role of financial incentives. Although traditional agency literature would indicate that financial incentives could motivate efforts in the desired direction, more recent work (Gibbons, 1998) has argued for the consideration of "non-financial" motivational factors. Study of such factors that could be manipulated by an organization to motivate credible disclosure of process details awaits future research. 


\section{ACKNOWLEDGEMENT}

We acknowledge the helpful comments of Balasubramanian Ramesh, Robert Ramsay, Ram Sriram and Ping Zhang. Any remaining errors are our own.

\section{REFERENCES}

1. Alavi, M., \& Leidner, D.E., (2001). Review: Knowledge Management and Knowledge Management Systems: Conceptual Foundations and Research Issues. MIS Quarterly, 25(1), 107-136.

2. Balakrishnan, R., Sivaramakrishnan, K., \& Surysekar., K. (2004). Short-Term Contracts, Long-Term Actions, and Information System Design. Journal of Accounting, Auditing \& Finance, 19(2), 117-131.

3. Bernhardt, S. A., \& McMulley, G. A. (2000). Knowledge management and pharmaceutical development teams: Using writing to guide science. IEEE Transactions on Professional Communication, 43(1).

4. Church, B. K., Nagao, D., \& Surysekar, K. (1999). Continued Support for Poorly Performing Capital Projects: A Multi-Period Experimental Study. Advances in Management Accounting, 8(1), 27-43.

5. Collier, B., DeMarco, T., \& Fearey, P. (1996). A defined process for project postmortem review. IEEE Software, 13(4), 65-72.

6. Fox, F., \& Staw, B. M. (1979). The trapped administrator: The effects of job insecurity and policy resistance upon commitment to a course of action. Administrative Science Quarterly, 24(3), 449-471.

7. Gibbins, M., \& Emby, C. (1985). Evidence on the Nature of Professional Judgment in Public Accounting. In A. R. Abdel-Khalik \& I. Solomon (Eds.), Auditing Research Symposium. Urbana-Champaign, IL: Champaign, Ill: Office of Accounting Research, University of Illinois at Urbana-Champaign.

8. Gibbons, R. (1998). Incentives in organization. The journal of Economic Perspectives, 12(4), 115-133.

9. Hoffman, V. B., \& Patton., J. M. (1997). Accountability, the Dilution Effect, and Conservatism in Auditors' Fraud Judgments. Journal of Accounting Research, 35(2), 227-237.

10. Johnson, V. E., \& Kaplan., S. E. (1991). Experimental Evidence on the Effects of Accountability on Auditor Judgments. Auditing: A Journal of Practice and Theory, 10(Supplement), 96-107.

11. Karina, A. (1998). Handbooks as a tool for organization learning: a case study. Journal of Engineering and Technology Management, 15(2), 201-228.

12. Kelley, H. H. (1967). Attribution Theory in Social Psychology. In Nebraska Symposium on Motivation (pp. 192-238). Lincoln, Nebraska: University of Nebraska Press.

13. Kennedy, J. (1993). Debiasing Audit Judgment with Accountability: A Framework and Experimental Results. Journal of Accounting Research, 31(2), 231-245.

14. Kerth, N. (2000). The ritual of retrospectives - how to maximize group learning by understanding past projects. Software testing \& quality engineering, 2(5), 53-57.

15. Kruchten, P. (2003). The Rational Unified Process: An Introduction (3rd ed.): Pearson Education.

16. Kulpa, M. K., \& Johnson, K. A. (2003). Interpreting the CMMI: A Process Improvement Approach. Boca Raton, Florida: Auerbach Publication.

17. Larman, C. (2004). Agile \& Iterative Development, A Manager's Guide. Boston, MA: Addison Wesley, Pearson Education Group.

18. Lerner, J. S., \& Tetlock, P. E. (1999). Accounting for the Effects of Accountability. Psychological Bulletin, 125(2), 255-275.

19. Lipshitz, R., \& Barak, D. (1995). Hindsight wisdom Outcome knowledge and the evaluation of decisions. Acta Psychologica, 88(1), 105-125.

20. Liu, X., Dooley, K. J., \& Anderson, J. C. (1995). Combining process knowledge for continuous quality improvement. IIE Transaction, 27(6), 811-820.

21. Markus, L. (2001). Toward a Theory of Knowledge Reuse: Types of Knowledge Reuse Situations and Factors in Reuse Success. Journal of Management Information Systems, 18(1), 57-93.

22. Nonaka, I. (1994). A dynamic theory of organizational knowledge creation. Organization Science, 5(1), 1438.

23. Nonaka, I., \& Konno, N. (1998). The concept of "ba": Building a foundation for knolwedge creation. California Management Review, 40(3), 40-54. 
24. Nonaka, I., Toyama, R., \& Konno, N. (2000). SECI, Ba and Leadership: a Unified Model of Dynamic Knowledge Creation. Long Range Planning, 33(1), 5-34.

25. Peecher, M. E. (1996). The Influence of Auditors' Justification Processes on their Decisions: A Cognitive Model and Experimental Evidence. Journal of Accounting Research, 34(1), 125-140.

26. Ramaprasad, A., \& Rai, A. (1996). Envisioning management of information. Omega, $24(2), 179-201$.

27. Ramesh, B. (2002). Process Knowledge Management with Traceability. IEEE Software, 19(3).

28. Ramesh, B., \& Surysekar, K. (2003). On the role of accountability and incentives in obtaining quality process documentation. Review of Business Information Systems 7(4), 41-50.

29. Schindler, M., \& Eppler, M. J. (2003). Harvesting project knowledge: a review of project learning methods and success factors. International Journal of Project Management, 21(3), 219-228.

30. Siegel-Jacobs, K., \& Yates, J. F. (1996). Effects of procedural and outcome acccountability on judgement quality. Organizational Behavior and Human Decision Processes, 1(1), 1-17.

31. Simonson, I., \& Staw, B. M. (1992). Deescalation strategies: a comparison of techniques for reducing commitment to losing course of action. Journal of Applied Psychology, 77(4), 419-426.

32. Stumpf, R. V., \& Teague, L. C. (2004). Object-Oriented Systems Analysis and Design with UML. Upper Saddle River, New Jersey: Pearson Education, Inc.

33. Tetlock, P. E. (1983). Accountability and complexity of thought. Journal of Personality and Social Psychology, 45(1), 74-83.

34. Tetlock, P. E. (1985). Accountability: The neglected social context of judgement and choice. In B. M. Staw \& L. Cummings (Eds.), Research in organizational behavior (Vol. 1, pp. 297-332).

35. Tetlock, P. E., Skitka, L., \& Boettger, R. (1989). Social and Cognitive Strategies for Coping with Accountability: Conformity, Complexity , and Bolstering. Journal of Personality and Social Psychology, 57(4), 632-640.

36. Turner, C. W. (2001). Accountability Demands and the Auditor's Evidence Search Strategy: The Influence of Reviewer Preferences and the Nature of the Response (Belief vs. Action). Journal of Accounting Research, 39(3), 683-706. 
NOTES 